\title{
Compact Chemical Mechanism for Autoignition and Combustion of Methylcyclohexane under Engine Relevant Conditions
}

\author{
Tong Yao, ${ }^{\dagger} \ddagger \odot$ Bei-Jing Zhong, ${ }^{*}$, and Kai Hong Luo ${ }^{* \dagger, \S}$ \\ ${ }^{\dagger}$ Center for Combustion Energy, Key Laboratory for Thermal Science and Power Engineering of Ministry of Education, Department \\ of Thermal Engineering, Tsinghua University, Beijing 100084, China \\ ${ }^{\ddagger}$ Department of Engineering Mechanics, Tsinghua University, Beijing 100084, China \\ ${ }^{\S}$ Department of Mechanical Engineering, University College London, Torrington Place, London WC1E 7JE, U.K.
}

\section{Supporting Information}

ABSTRACT: A compact chemical kinetic mechanism for autoignition and combustion of methylcyclohexane (MCH) was developed and validated for a wide range of conditions, especially for low temperatures and high pressures that are most relevant to real engines. The mechanism was constructed in steps. An improved $\mathrm{C}_{5}-\mathrm{C}_{7}$ submechanism (26 species and 90 reactions) was first developed to describe fuel-cracking to form smaller fragments under high temperatures. Five modules of the $\mathrm{C}_{5}$ - $\mathrm{C}_{7}$ submechanism were considered separately, and the rate constants were carefully estimated. A semiglobal low-temperature submechanism was developed to improve prediction of the negative temperature coefficient behaviors, which contained 4 species and 11 reactions. Isomers of intermediate radicals and fast reactions were lumped to obtain the minimal low-temperature submechanism. Combined with a simplified $\mathrm{C}_{0}-\mathrm{C}_{4}$ kernel (40 species and 276 reactions), the final mechanism consists of 70 species and 377 reactions. Validations of the newly developed mechanism were performed using amounts of experimental data, including ignition delays in shock tubes and rapid compression machines, under a wide range of temperatures (650-2000 K), pressures (1-50 atm), and equivalence ratios (0.5-2.0), and $\mathrm{OH}$ concentration histories in high pressure shock tubes. Furthermore, experimental data of species concentrations and flame speeds in laminar premixed flames were also used for validation. The present mechanism showed good accuracy in predicting ignition and combustion properties over a range of parameters. Simulations using other detailed $\mathrm{MCH}$ mechanisms were also carried out for comparison.

\section{INTRODUCTION}

Practical fossil fuels are complex mixtures consisting of a large number of hydrocarbons including $n$-alkanes, iso-alkanes, cycloalkanes, and aromatics, among other species. Cycloalkanes have received increasing attention over recent years because they are important components of practical fuels such as gasoline, diesel, and jet fuels. For instance, 20\% of Jet-A fuel, $40 \%$ of diesel, and $60 \%$ of PR-1 fuel are composed of cycloalkanes. ${ }^{1}$ Cycloalkanes play a significant role in combustion chemistry of practical fuels, and the kinetics of cycloalkanes is critical to representing the reactivity of gasoline, diesel, and jet fuels. In order to simulate combustion in real engines accurately, chemical kinetic mechanisms for key component classes of practical and surrogate fuels are required. Methylcyclohexane $(\mathrm{MCH})$ is a representative cycloalkane with a 6 single bonded carbon ring with a methyl group, and always used as a component of surrogate fuels. ${ }^{2,3} \mathrm{MCH}$ is also considered as a starting point for the development of chemical kinetic mechanisms for other cycloalkanes. ${ }^{4}$

Recently, some experimental measurements and kinetic modeling studies have been focused on autoignition and combustion of $\mathrm{MCH}^{4-13}$ Ignition delays were measured behind reflected shock waves and rapid compression machines (RCMs) for $\mathrm{MCH}$ at various pressures, temperatures, and equivalence ratios by different authors. Among them, Vanderover et al. ${ }^{5}$ and Vasu et al. ${ }^{6,7}$ studied the autoignition of $\mathrm{MCH}$ in shock tubes under intermediate and high temperatures $(800-1500 \mathrm{~K})$, elevated pressures $(10-50 \mathrm{~atm})$, and various equivalence ratios (0.25-2.0). Mittal et al. ${ }^{8}$ and Weber et al. ${ }^{9}$ conducted autoignition experiments in heated RCMs with $\mathrm{MCH} / \mathrm{O}_{2} / \mathrm{N}_{2} / \mathrm{Ar}$ mixtures at low-to-intermediate temperatures $(680-900 \mathrm{~K})$, high pressures $(15.1-50 \mathrm{bar})$, and different equivalence ratios $(0.5-1.5)$. These experimental data of ignition delays have provided a helpful database for development and validation of $\mathrm{MCH}$ chemical mechanisms under engine relevant conditions. Other experimental data include $\mathrm{OH}$ time histories during the oxidation of $\mathrm{MCH}^{7}$ laminar flame speeds of $\mathrm{MCH} /$ air premixed flames, ${ }^{10,11}$ and species profiles in laminar premixed MCH combustion. ${ }^{12,13}$

In the meantime, several chemical mechanisms have been developed in recent studies. ${ }^{4,12,14-16}$ Orme et al. ${ }^{14}$ developed a mechanism for high-temperature oxidation of $\mathrm{MCH}$. The mechanism contains 190 species and 904 reactions. Wang et al. ${ }^{12}$ developed a combustion mechanism of $\mathrm{MCH}$ with 249 species and 1570 reactions. The mechanism was validated using experimental data of species distributions in premixed flames, ignition delays, and laminar flame speeds. However, the above two mechanisms only consider species and reactions of hightemperature oxidation. Pitz et al. ${ }^{4}$ developed a low-to-high temperature oxidation mechanism to predict $\mathrm{MCH}$ autoignition in RCM based on the high-temperature mechanism by Orme et al. ${ }^{14}$ This detailed mechanism consists of 1001

Received: April 28, 2017

Revised: August 28, 2017

Published: September 11, 2017 
species and 4436 reactions. Narayanaswamy et al. ${ }^{15}$ developed a skeletal level mechanism which consists of 253 species and 1000 reactions. Although these two mechanisms can account for a wide range of temperatures, the size prevents them from being useful in multidimensional simulations of engine combustion. A large proportion of the species in the detailed mechanisms ${ }^{4,15}$ are intermediate species involved in lowtemperature oxidation. In order to obtain compact mechanisms that can describe low-temperature ignition behaviors, lowtemperature reaction paths can be lumped into a simplified formation to reproduce global quantities of low-temperature ignition (e.g., ignition delays), but not to describe details of low-temperature oxidation. ${ }^{17}$ Several skeletal mechanisms with lumped low-temperature chemistry have been developed based on this assumption. ${ }^{17-19}$ However, these mechanisms are focused on $n$-alkanes. Wang et al. ${ }^{16}$ developed a detailed mechanism called JetSurF 2.0 with lumped low-temperature chemistry for describing oxidation of cyclohexane and alkylcyclohexanes up to $n$-butylcyclohexane including 352 species and 2083 reactions. However, this mechanism does not closely predict the ignition delays under low temperatures. Lumped low-temperature chemistry for $\mathrm{MCH}$ needs to be further optimized.

In this paper, a compact skeletal mechanism is developed for describing $\mathrm{MCH}$ autoignition and combustion using a decoupling strategy. For autoignition and combustion of large hydrocarbons, fuel decomposition to smaller fragments is always fast and can be decoupled from oxidation kinetics of the smaller fragments. ${ }^{20}$ The decoupling strategy has been employed in the development of skeletal mechanisms of $n$ alkanes like $n$-decane, $n$-dodecane, ${ }^{20-22}$ resulting in small skeletal mechanisms that are promising for further reduction or direct use in multidimensional turbulent combustion simulations. The decoupling strategy is successfully extended to $\mathrm{MCH}$ in the present work. Three submechanisms are developed separately and then assembled to form the final mechanism. An improved $\mathrm{C}_{5}-\mathrm{C}_{7}$ submechanism consisting of 26 species and 90 reactions is first developed to describe the fuel-cracking process. An optimized semiglobal low-temperature submechanism (4 species and 11reactions) and a simplified $\mathrm{C}_{0}-\mathrm{C}_{4}$ kernel (40 species and 276 reactions) are then developed and merged to the $\mathrm{C}_{5}-\mathrm{C}_{7}$ submechanism, leading to a compact mechanism consisting of 70 species and 377 reactions. The newly developed mechanism is validated against detailed mechanisms and available experimental measurements including (1) ignition delays at high and low temperatures, (2) $\mathrm{OH}$ time histories at high temperatures in shock tubes, (3) premixed flame structures under various equivalence ratios, and (4) laminar flame speeds of premixed flames.

\section{CONSTRUCTION OF THE SKELETAL MECHANISM}

2.1. $C_{5}-C_{7}$ Submechanism. For high-temperature chemistry of $\mathrm{MCH}$, the $\mathrm{C}_{5}-\mathrm{C}_{7}$ submechanism consists of five modules including unimolecular decomposition of $\mathrm{MCH}, \mathrm{H}$ atom abstractions of $\mathrm{MCH}$, ring-opening of cyclohexyl and cyclic $\mathrm{C}_{7} \mathrm{H}_{13}$ radicals, decomposition of alkenyl radicals, and decomposition and $\mathrm{H}$-abstractions of alkenes. Construction details of each module are described below.

2.1.1. Unimolecular Decomposition of $\mathrm{MCH}$. Unimolecular decomposition of $\mathrm{MCH}$ includes $\mathrm{CH}_{3}$ loss to form cyclic $\mathrm{C}_{6} \mathrm{H}_{11}$ and dissociation of $\mathrm{C}-\mathrm{C}$ bonds on the ring to form biradicals $\mathrm{C}_{7} \mathrm{H}_{14}$. The biradicals undergo internal $\mathrm{H}$-shift and lead to the formation of heptenes and methylhexenes. Due to symmetry of the $\mathrm{MCH}$ molecule, three kinds of $\mathrm{C}_{7} \mathrm{H}_{14}$ biradicals form and turn into six different heptene and methylhexenes isomers. ${ }^{14}$ According to previous studies, ${ }^{16,23}$ 2-heptene $\left(2-\mathrm{C}_{7} \mathrm{H}_{14}\right)$ and 1heptene $\left(\mathrm{C}_{7} \mathrm{H}_{14}\right)$ account for most of the $\mathrm{MCH}$ isomerization products. In order to reduce the number of species, only these two heptene isomers $\mathrm{C}_{7} \mathrm{H}_{14}$ and $2-\mathrm{C}_{7} \mathrm{H}_{14}$ are considered. The unimolecular decomposition reactions are shown in Table 1.

Table 1. Unimolecular Decomposition Reactions of $\mathrm{MCH}$

$\begin{array}{ccc}\text { Formula } & \text { Structure } & \begin{array}{c}\text { Reaction } \\ \text { No. }\end{array} \\ \mathrm{MCH}=c-\mathrm{C}_{6} \mathrm{H}_{11}+\mathrm{CH}_{3} & \text { (R1) } \\ \mathrm{MCH}=\mathrm{C}_{7} \mathrm{H}_{14} & \text { (R2) }\end{array}$

There are few experimental and theoretical studies on R1, and the rate constant in the Orme et al. ${ }^{14}$ mechanism is determined using the combination rate for methyl addition to an isopropyl radical taken from the work of Tsang. ${ }^{24}$ However, this rate constant does not consider the pressure-dependent fall-off effect. In the present work, rate constant parameters for the combination of methyl and isopropyl radicals from USC Mech $\mathrm{II}^{25}$ are used to accommodate a wide range of pressures. In Orme et al. ${ }^{14}$ and Pitz et al. ${ }^{4}$ mechanisms, reaction rates of $\mathrm{R} 2$ and $\mathrm{R} 3$ are underestimated for the consumption of $\mathrm{MCH}$, leading to poor prediction of $\mathrm{OH}$ profiles in the $\mathrm{MCH}$ oxidation. Rate constants of $\mathrm{R} 2$ and $\mathrm{R} 3$ in the present mechanism are taken from JetSurF $2.0,{ }^{16}$ which leads to a better prediction of $\mathrm{OH}$ profiles as will be seen in section 3.3.

2.1.2. H-atom Abstraction of $M C H$. In the oxidation process, $\mathrm{H}$-abstraction reactions by free radicals' attack are critical for the consumption of $\mathrm{MCH}$ at both low and high temperatures. Due to less importance of abstractions by hydrocarbon radicals, e.g., $\mathrm{C}_{2} \mathrm{H}_{5}, \mathrm{C}_{3} \mathrm{H}_{7}$, etc., only reactions with radicals $\mathrm{H}, \mathrm{CH}_{3}, \mathrm{O}_{2}, \mathrm{HO}_{2}, \mathrm{OH}, \mathrm{O}$ are considered here. The $\mathrm{MCH}$ molecule possesses five different $\mathrm{H}$-abstraction sites; reactions with each of the above radicals produce five cyclic $\mathrm{C}_{7} \mathrm{H}_{13}$ radicals, as is shown in Table 2. $\mathrm{R}$ represents $\mathrm{H}, \mathrm{CH}_{3}$, $\mathrm{O}_{2}, \mathrm{HO}_{2}, \mathrm{OH}, \mathrm{O}$, respectively.

Rate constants of these reactions depend on the carbon site type of $\mathrm{H}$-abstraction and the various attacking radicals. The sites can be divided into three types, which are the primary,

Table 2. H-atom Abstraction of $\mathrm{MCH}$

$\begin{array}{ccc}\text { Formulas } & \begin{array}{c}\text { Reaction } \\ \text { No. }\end{array} \\ \mathrm{MCH}+\mathrm{R}=\mathrm{CH}_{2}-c-\mathrm{C}_{6} \mathrm{H}_{11}+\mathrm{RH} & \text { (R4-R9) } \\ \mathrm{MCH}+\mathrm{R}=1-\mathrm{CH}_{3}-c-\mathrm{C}_{6} \mathrm{H}_{10}+\mathrm{RH} & & \text { (R10-R15) } \\ \mathrm{MCH}+\mathrm{R}=3-\mathrm{CH}_{3}-c-\mathrm{C}_{6} \mathrm{H}_{10}+\mathrm{RH} & & \\ \text { (R216-R21) }\end{array}$


secondary, and tertiary carbon sites, according to the different numbers of $\mathrm{H}$ atoms present on the sites. ${ }^{26}$ Besides the carbon sites and attacking radicals, rate constants of $\mathrm{H}$-abstraction reactions also depend on the local environment of the $\mathrm{H}$ atoms to be abstracted. ${ }^{27} \mathrm{H}$-abstraction from the same carbon site of different hydrocarbon molecules is slightly different. In the JetSurF 2.0 mechanism, ${ }^{16}$ the rate constants were referred to analogous reactions of $n$-propane and iso-butane, and slight changes were made to account for different molecular structures. The kinetic data used in the present mechanism are derived from recommendations of JetSurF 2.0. ${ }^{16}$

2.1.3. Ring-Opening Reactions Cyclohexyl and Cyclic $\mathrm{C}_{7} \mathrm{H}_{13}$. After $\mathrm{CH}_{3}$ loss and $\mathrm{H}$-atom abstraction of $\mathrm{MCH}$, cyclohexyl $\left(\mathrm{c}_{-} \mathrm{C}_{6} \mathrm{H}_{11}\right)$ and cyclic $\mathrm{C}_{7} \mathrm{H}_{13}$ radicals arise and then undergo ring-opening reactions, which play a dominant role in the consumption of $\mathrm{c}_{-} \mathrm{C}_{6} \mathrm{H}_{11}$ and cyclic $\mathrm{C}_{7} \mathrm{H}_{13}$ radicals. The ring-opening of $c-\mathrm{C}_{6} \mathrm{H}_{11}$ forms hex-5-en-1-yl $\left(p-\mathrm{C}_{6} \mathrm{H}_{11}\right)$, and cyclic $\mathrm{C}_{7} \mathrm{H}_{13}$ radicals producing alkenyl $\mathrm{C}_{7} \mathrm{H}_{13}$ radicals are shown in Table 3. Due to the symmetric structures of $\mathrm{CH}_{2}-\mathrm{c}$ -

Table 3. Ring-Opening Reactions of Cyclohexyl and Cyclic $\mathrm{C}_{7} \mathrm{H}_{13}$

Formulas
$c-\mathrm{C}_{6} \mathrm{H}_{11}=p-\mathrm{C}_{6} \mathrm{H}_{11}$
$2-\mathrm{CH}_{3}-c-\mathrm{C}_{6} \mathrm{H}_{10}=2-\mathrm{CH}_{3}-p-\mathrm{C}_{6} \mathrm{H}_{10}$
$2-\mathrm{CH}_{3}-c-\mathrm{C}_{6} \mathrm{H}_{10}=2-\mathrm{C}_{7} \mathrm{H}_{13}$
$3-c-\mathrm{C}_{6} \mathrm{H}_{10}=3-\mathrm{CH}_{3}-p-\mathrm{C}_{6} \mathrm{H}_{10}$

$\mathrm{C}_{6} \mathrm{H}_{11}, 1-\mathrm{CH}_{3}-c-\mathrm{C}_{6} \mathrm{H}_{10}$, and 4- $\mathrm{CH}_{3}-c-\mathrm{C}_{6} \mathrm{H}_{10}$, one alkenyl $\mathrm{C}_{7} \mathrm{H}_{13}$ radical isomer is produced from these three cyclic $\mathrm{C}_{7} \mathrm{H}_{13}$ through R35-R36 and R41, respectively. Two alkenyl $\mathrm{C}_{7} \mathrm{H}_{13}$ radical isomers derive from $2-\mathrm{CH}_{3}-c-\mathrm{C}_{6} \mathrm{H}_{10}, 3-\mathrm{CH}_{3}-c-\mathrm{C}_{6} \mathrm{H}_{10}$ through $\mathrm{R} 37-\mathrm{R} 38$ and $\mathrm{R} 39-\mathrm{R} 40$, respectively.

A lot of theoretical and experimental studies have focused on the ring-opening of small alkyl radicals, like cyclopropyl ${ }^{28}$ and cyclopropylcarbinyl. $^{29-31}$ Matheu et al. ${ }^{32}$ proposed high pressure limit rate rules for radical additions and ringopening/closing reactions, including cyclobutyl, cyclopentyl, and cyclohexyl. In the Orme et al. mechanism, ${ }^{14}$ ring-opening reactions were written in the reverse intramolecular alkenyl radical ring closure direction; rate constants were referred to rate constant expressions of Matheu et al. ${ }^{32}$ for primary carbon radical addition to an external doubly bound carbon atom with activation energy alteration. In a more recent study, Sirjean et al. $^{33}$ investigated rate constants of ring-opening reactions of unbranched cycloalkyl radcials $\left(\mathrm{C}_{3}-\mathrm{C}_{7}\right)$ and branched cycloalkyl radicals $\left(\mathrm{C}_{4}-\mathrm{C}_{5}\right)$. In the present mechanism, rate constants of ring-opening reactions (R34-R41) are taken from Sirjean et al. $^{3}$
2.1.4. Decomposition of the Alkenyl Radicals. For the decomposition reactions of alkenyl radicals $\mathrm{C}_{7} \mathrm{H}_{13}, \mathrm{C}_{6} \mathrm{H}_{11}$, and $\mathrm{C}_{5} \mathrm{H}_{9}, \beta$-scissions of the $\mathrm{C}-\mathrm{C}$ bond take place to produce alkyl (alkenyl) radicals and diolefins (alkenes). It is worth noting that unimolecular isomerization reactions through five-, six-, and seven-membered cyclic transition complexes $(1,4 / 1,5 / 1,6 \mathrm{H}$ shifts) are important and can compete with its thermal decomposition. ${ }^{34}$ However, a large number of species and reactions are involved if all possible isomerization and decomposition reactions of $\mathrm{C}_{6} \mathrm{H}_{11}$ (hex-5-en-1-yl) and alkenyl $\mathrm{C}_{7} \mathrm{H}_{13}$ radicals are taken into account. According to reaction flux analysis performed by Orme et al., ${ }^{14}$ reaction pathways that contribute to $98 \%$ consumption of the hex-5-en-1-yl and alkenyl $\mathrm{C}_{7} \mathrm{H}_{13}$ radicals are retained in the present mechanism along with the associated species and reactions. The loss of removing the less important reaction pathways is evaluated and found to be negligible to the predictions of autoignition and laminar flames. The retained isomerization and decomposition reactions of hex-5-en-1-yl and alkenyl $\mathrm{C}_{7} \mathrm{H}_{13}$ radicals are shown in Table 4. R42 is the isomerization through 1,4 H-shift. R43-

Table 4. Decomposition of the Hex-5-en-1-yl and Alkenyl $\mathrm{C}_{7} \mathrm{H}_{13}$

2-CH3-

$\mathrm{R} 55$ are decomposition reactions of hex-5-en-1-yl and alkenyl $\mathrm{C}_{7} \mathrm{H}_{13}$ radicals to form smaller alkenyls and alkenes $\left(\mathrm{C}_{2} \mathrm{H}_{4}\right.$, $\left.\mathrm{C}_{3} \mathrm{H}_{6}\right)$, and diolefins and alkyls $\left(\mathrm{CH}_{3}, \mathrm{C}_{2} \mathrm{H}_{5}, \mathrm{C}_{3} \mathrm{H}_{7}\right)$. As for alkenyl $\mathrm{C}_{5} \mathrm{H}_{9}$ radicals including $p-\mathrm{C}_{5} \mathrm{H}_{9}, s a-\mathrm{C}_{5} \mathrm{H}_{9}, s-\mathrm{C}_{5} \mathrm{H}_{9}$, and $\mathrm{CH}_{2}-p-\mathrm{C}_{4} \mathrm{H}_{7}$, they are produced from the decomposition of alkenyl $\mathrm{C}_{7} \mathrm{H}_{13}$ radicals, and consumed by $\mathrm{C}-\mathrm{C}$ bond decomposition and reacting with $\mathrm{H}$ atom or $\mathrm{HO}_{2}$ radicals to produce smaller radicals (not shown in Table 4).

Matheu et $\mathrm{al}^{32}$ investigated the intramolecular hydrogen transfer ( $\mathrm{H}$-Shift) rules, which were used in the $\mathrm{MCH}$ oxidation mechanism of Orme et al. ${ }^{14}$ and cyclohexane oxidation mechanism of Silke et al. ${ }^{35}$ In a more recent study of 
isomerization of branched hydrocarbons, McGivern et al. ${ }^{36}$ presented the rate constant of the 1,4-H shift reaction of 4methyl-1-pentyl radicals, which is more similar to $\mathrm{R} 42$. The rate constant of R46 in the present mechanism is taken from McGivern et al. ${ }^{36}$

Rate constants for alkenyls decomposition in the Orme et al. ${ }^{14}$ mechanism were estimated in the exothermic direction, and taken from a study for $\mathrm{C}_{1}-\mathrm{C}_{4}$ alkyl radical decompositions by Curran et al. ${ }^{37}$ In a more recent study, Tsang et al. ${ }^{38}$ measured a series of decomposition and isomerization reactions of octyl radicals. Rate constants of reactions R43-R55 are referred to the analogous decomposition reactions of octyl radicals from Tsang et al. ${ }^{38}$

2.1.5. Decomposition and H-Abstraction of Alkenes. Decomposition and $\mathrm{H}$-abstraction reactions of alkene $\mathrm{C}_{7} \mathrm{H}_{14}$ are shown in Table 5. Heptenes $\left(\mathrm{C}_{7} \mathrm{H}_{14}\right.$ and $\left.\mathrm{C}_{7} \mathrm{H}_{14}-2\right)$ react

Table 5. Decomposition and H-Abstraction of Alkene $\mathrm{C}_{7} \mathrm{H}_{14}$

(Rormulas

mainly via thermal decomposition reactions (R56-R58). Haddition to heptenes and the following decomposition are lumped into one reaction, expressed by R59-R61. Heptenes can also react with $\mathrm{R}$ radicals $\left(\mathrm{H}, \mathrm{O}, \mathrm{O}_{2}, \mathrm{CH}_{3}, \mathrm{OH}, \mathrm{HO}_{2}\right)$ by $\mathrm{H}$ abstraction (R62-R67) to produce alkenyl $\mathrm{C}_{7} \mathrm{H}_{13}$ radicals. $\mathrm{R} 68$ is a lumped reaction that consumes heptenes through $\mathrm{OH}$ radicals addition and decomposition. Rate constants of these reactions are taken from JetSurF 2.0. ${ }^{16}$ Decomposition reactions of $\mathrm{C}_{6} \mathrm{H}_{10}\left(1,5-\mathrm{C}_{6} \mathrm{H}_{10}\right)$ and $\mathrm{C}_{5} \mathrm{H}_{8}\left(2-\mathrm{CH}_{3}-p-\mathrm{C}_{4} \mathrm{H}_{5}\right.$ and $1,3-\mathrm{C}_{5} \mathrm{H}_{8}$ ) follow similar patterns and are not shown here.

2.2. A Minimal Low-Temperature Submechanism. According to the studies of Pitz et al., ${ }^{4}$ the low-temperature reaction pathways of $\mathrm{MCH}$ oxidation are similar to $n$-alkanes. Reactions can be decoupled from high-temperature chemistry and lumped into a few steps for predicting ignition delays and cool flame behaviors (e.g., Negative Temperature Coefficient, NTC). The low-temperature submechanism in the present mechanism is lumped into 4 species and 11 reactions as shown in Table 6.

Under low-to-intermediate temperature conditions, the first step of the low-temperature chemistry sequence is the addition of $\mathrm{O}_{2}$ to cyclic $\mathrm{C}_{7} \mathrm{H}_{13}$ radicals to produce methylcyclohexyl peroxy $\left(\mathrm{C}_{7} \mathrm{H}_{13} \mathrm{O}_{2}\right)$ radicals. In order to reduce the mechanism, $\mathrm{C}_{7} \mathrm{H}_{13} \mathrm{O}_{2}$ isomers are lumped into one, as is recommended by Bikas and Peters. ${ }^{17} \mathrm{C}_{7} \mathrm{H}_{13} \mathrm{O}_{2}$ radicals undergo isomerization to produce methyl-cyclohexylhydroperoxy $\left(\mathrm{C}_{7} \mathrm{H}_{12} \mathrm{OOH}\right)$ through R74. The fraction of $\mathrm{C}_{7} \mathrm{H}_{12} \mathrm{OOH}$ radicals consuming through isomerization back to $\mathrm{C}_{7} \mathrm{H}_{13} \mathrm{O}_{2}$ (R75) is most responsible for
Table 6. Low-Temperature Reactions

\begin{tabular}{|c|c|c|}
\hline Formulas & Structure & $\begin{array}{l}\text { Reaction } \\
\text { No. }\end{array}$ \\
\hline $\mathrm{C}_{6} \mathrm{H}_{11} \mathrm{CH}_{2}+\mathrm{O}_{2}=\mathrm{C}_{7} \mathrm{H}_{13} \mathrm{O}_{2}$ & $\mathrm{O}_{2} \longrightarrow \mathrm{C}_{7} \mathrm{H}_{13}-\mathrm{O}-\dot{\mathrm{O}}$ & (R69) \\
\hline $1-\mathrm{C}_{6} \mathrm{H}_{10} \mathrm{CH}_{3}+\mathrm{O}_{2}=\mathrm{C}_{7} \mathrm{H}_{13} \mathrm{O}_{2}$ & $\mathrm{O}_{2} \longrightarrow \mathrm{C}_{7} \mathrm{H}_{13}-\mathrm{O}-\dot{\mathrm{O}}$ & (R70) \\
\hline $2-\mathrm{C}_{6} \mathrm{H}_{10} \mathrm{CH}_{3}+\mathrm{O}_{2}=\mathrm{C}_{7} \mathrm{H}_{13} \mathrm{O}_{2}$ & $\mathrm{O}_{2} \longrightarrow \mathrm{C}_{7} \mathrm{H}_{13}-\mathrm{O}-\dot{\mathrm{O}}$ & (R71) \\
\hline $3-\mathrm{C}_{6} \mathrm{H}_{10} \mathrm{CH}_{3}+\mathrm{O}_{2}=\mathrm{C}_{7} \mathrm{H}_{13} \mathrm{O}_{2}$ & $\mathrm{C}_{7} \mathrm{H}_{13}-\mathrm{O}-\dot{\mathrm{O}}$ & (R72) \\
\hline $4-\mathrm{C}_{6} \mathrm{H}_{10} \mathrm{CH}_{3}+\mathrm{O}_{2}=\mathrm{C}_{7} \mathrm{H}_{13} \mathrm{O}_{2}$ & $\mathrm{O}_{2} \longrightarrow \mathrm{C}_{7} \mathrm{H}_{13}-\mathrm{O}-\dot{\mathrm{O}}$ & (R73) \\
\hline $\mathrm{C}_{7} \mathrm{H}_{13} \mathrm{O}_{2} \rightarrow \mathrm{C}_{7} \mathrm{H}_{12} \mathrm{OOH}$ & $\mathrm{C}_{7} \mathrm{H}_{13}-\mathrm{O}-\dot{\mathrm{O}} \longrightarrow \dot{\mathrm{C}}_{7} \mathrm{H}_{12}-\mathrm{O}-\mathrm{OH}$ & (R74) \\
\hline $\mathrm{C}_{7} \mathrm{H}_{12} \mathrm{OOH} \rightarrow \mathrm{C}_{7} \mathrm{H}_{13} \mathrm{O}_{2}$ & $\dot{\mathrm{C}}_{7} \mathrm{H}_{12}-\mathrm{O}-\mathrm{OH} \longrightarrow \mathrm{C}_{7} \mathrm{H}_{13}-\mathrm{O}-\dot{\mathrm{O}}$ & (R75) \\
\hline $\mathrm{C}_{7} \mathrm{H}_{12} \mathrm{OOH}+\mathrm{O}_{2} \rightarrow \mathrm{O}_{2} \mathrm{C}_{7} \mathrm{H}_{12} \mathrm{OOH}$ & $\begin{array}{rl}\dot{\mathrm{C}}_{7} \mathrm{H}_{12}-\mathrm{O}-\mathrm{OH}+\mathrm{O}_{2} \longrightarrow & \mathrm{C}_{7} \mathrm{H}_{12}-\mathrm{O}-\mathrm{OH} \\
\mathrm{I} & \mathrm{O}-\dot{\mathrm{O}}\end{array}$ & (R76) \\
\hline $\mathrm{O}_{2} \mathrm{C}_{7} \mathrm{H}_{12} \mathrm{OOH} \rightarrow \mathrm{C}_{7} \mathrm{H}_{12} \mathrm{OOH}+\mathrm{O}_{2}$ & $\begin{array}{l}\mathrm{C}_{7} \mathrm{H}_{12}-\mathrm{O}-\mathrm{OH} \longrightarrow \dot{\mathrm{C}}_{7} \mathrm{H}_{12}-\mathrm{O}-\mathrm{OH}+\mathrm{O}_{2} \\
\mathrm{l}-\dot{\mathrm{O}}\end{array}$ & (R77) \\
\hline $\mathrm{O}_{2} \mathrm{C}_{7} \mathrm{H}_{12} \mathrm{OOH}=\mathrm{OC}_{7} \mathrm{H}_{11} \mathrm{OOH}+\mathrm{OH}$ & $\begin{array}{ll}\mathrm{C}_{7} \mathrm{H}_{12}-\mathrm{O}-\mathrm{OH} \longrightarrow \\
\mathrm{O}_{\mathrm{O}}-\dot{\mathrm{O}} & \mathrm{C}_{7} \mathrm{H}_{11}-\mathrm{O}-\mathrm{OH}+\dot{\mathrm{OH}} \\
\mathrm{O} & \mathrm{O}\end{array}$ & (R78) \\
\hline $\begin{array}{c}\mathrm{OC}_{7} \mathrm{H}_{11} \mathrm{OOH} \rightarrow \\
\mathrm{CH}_{2} \mathrm{O}+\mathrm{C}_{2} \mathrm{H}_{3}+\mathrm{C}_{2} \mathrm{H}_{4}+\mathrm{CH}_{2} \mathrm{CO}+\mathrm{OH}\end{array}$ & $\begin{array}{l}\mathrm{C}_{7} \mathrm{H}_{11}-\mathrm{O}-\mathrm{OH} \longrightarrow \mathrm{CH}_{2} \mathrm{O}+\dot{\mathrm{C}}_{2} \mathrm{H}_{3}+\mathrm{C}_{2} \mathrm{H}_{4}+\mathrm{CH}_{2} \mathrm{CO}+\dot{\mathrm{O} H} \\
\mathrm{O}\end{array}$ & (R79) \\
\hline
\end{tabular}

the prediction of the NTC region-ignition delays in the NTC region are very sensitive to this reaction. Another important reaction pathway of $\mathrm{C}_{7} \mathrm{H}_{12} \mathrm{OOH}$ radicals is $\mathrm{O}_{2}$ addition to produce $\mathrm{O}_{2} \mathrm{C}_{7} \mathrm{H}_{12} \mathrm{OOH}$ through $\mathrm{R} 76 . \mathrm{O}_{2} \mathrm{C}_{7} \mathrm{H}_{12} \mathrm{OOH}$ then undergoes decomposition to release $\mathrm{OH}$ and produce keto hydroperoxide $\left(\mathrm{OC}_{7} \mathrm{H}_{11} \mathrm{OOH}\right)$ through $\mathrm{R} 78$. The generation of $\mathrm{OH}$ leads to chain branching and accelerates the autoignition process. $\mathrm{OC}_{7} \mathrm{H}_{11} \mathrm{OOH}$ then decomposes to generate $\mathrm{OH}$, vinyl radical $\left(\mathrm{C}_{2} \mathrm{H}_{3}\right)$, ethylene, formaldehyde, and $\mathrm{CH}_{2} \mathrm{CO}$ through R79.

The lumped low-temperature submechanism is developed to reproduce global quantities of low-temperature ignition (e.g., ignition delays), but not to describe the detailed lowtemperature oxidation process. The rate constants of the reactions are referred to analogous reactions in our previous study. $^{22}$

2.3. Assembly of the Mechanism. In order to obtain a compact $\mathrm{C}_{0}-\mathrm{C}_{4}$ submechanism, reaction flow analysis (RFA) ${ }^{39}$ and sensitivity analysis (SA) ${ }^{40,41}$ are used to conduct a reduction based on a skeletal $\mathrm{C}_{0}-\mathrm{C}_{4}$ mechanism developed by Wang, ${ }^{42}$ which consists of 56 species and 428 reactions. On the basis of RFA, the contribution of each reaction to the generation and consumption of each species is quantified. Reactions that contribute, e.g., $5 \%$, to the total consumption of species are removed. SA is then employed to quantify the sensitivity of reactions to ignition delays, laminar flame speeds, and species profiles in premixed flames of $\mathrm{MCH}$. Reaction pathways that have little influence on ignition delays, laminar flame speeds, and species profiles are removed along with the associated species and reactions. Sixteen species and 152 reactions are removed from the skeletal $\mathrm{C}_{0}-\mathrm{C}_{4}$ mechanism of Wang. ${ }^{42} \mathrm{~A}$ new $\mathrm{C}_{0}-\mathrm{C}_{4}$ kernel for $\mathrm{MCH}$ containing 40 species and 276 reactions is thereby developed. Combined with the $\mathrm{C}_{5^{-}}$ $\mathrm{C}_{7}$ submechanism, a mechanism of 66 species and 366 reactions is obtained to describe the high-temperature oxidation of $\mathrm{MCH}$.

Low-temperature reactions are chemically lumped into a small submechanism that involves only 4 species and 11 

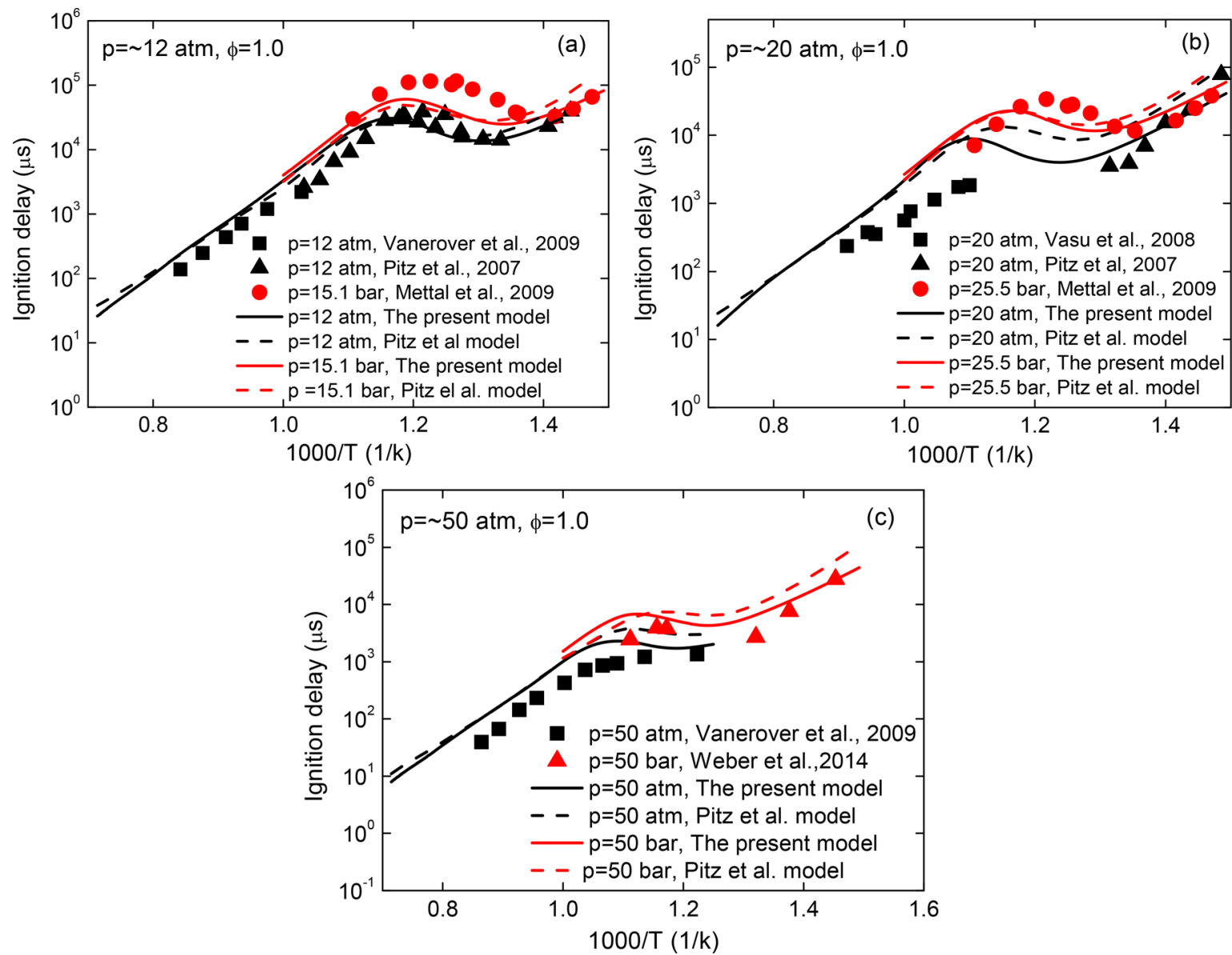

Figure 1. Comparison of experimental ${ }^{4-9}$ and calculated ignition delays of $\mathrm{MCH}$ at stoichiometric ratio and various pressures: (a) $p=\sim 12$ atm, (b) $p=\sim 20$ atm, (c) $p=\sim 50$ atm.

reactions. Rate constants are optimized through sensitivity analysis to fit experimental measurements and mainly the detailed Pitz et al. ${ }^{4}$ mechanism calculations under a wide array of conditions. The same optimization technique is employed in our previous study. ${ }^{22}$ Combined with the high-temperature mechanism, a final mechanism containing 70 species and 377 reactions is obtained, which can be found in the Supporting Information.

\section{VALIDATIONS OF THE MECHANISM}

In this section, validations of the newly developed mechanism are performed to evaluate the abilities to predict $\mathrm{MCH}$ ignition and combustion characteristics. Experimental data obtained from different reactors are used for comparison including (i) ignition delays from shock tube and rapid compression machine (RCM), (ii) $\mathrm{OH}$ species histories from high pressure shock tube, (iii) species concentration profiles in laminar premixed flames, and (iv) laminar flame speeds obtained at different pressures.

Simulations of ignition in shock tubes and RCMs are conducted using the SENKIN program ${ }^{43}$ with the assumption of constant-volume, homogeneous, and adiabatic conditions. This assumption is commonly used in the literature. ${ }^{5-7}$ Ignition delays are defined as the time at which the maximum temperature gradient is reached. The PREMIX program ${ }^{44}$ is employed for the simulations of species profiles and flame speeds in laminar premixed flames. A mixture-average transport model including thermal diffusion effect is employed in the simulations.

3.1. Autoignition Delays at High Pressures. The present mechanism is first applied to reproduce a great deal of experimental results of ignition delays obtained in shock tubes $^{5-7,14}$ and $\mathrm{RCMs}^{4,8,9}$ under various temperatures, pressures, and equivalence ratios. Figures 1 and 2 show the comparison of experimental data and predicted ignition delays using the present mechanism and the detailed Pitz et al. ${ }^{4}$ mechanism.

Figure 1a presents the comparison between experimental data and the simulated results at stoichiometric ratio and $p=$ $\sim 12$ atm. At high temperatures, $T>1000 \mathrm{~K}$, Vanderover et al. ${ }^{5}$ measured ignitions delays in a shock tube at $p=12 \mathrm{~atm}$. At low temperatures, $T<1000 \mathrm{~K}$, Pitz et al. ${ }^{4}$ and Mittal et al. ${ }^{8}$ measured ignition delays in RCMs at $p=10$ atm and $p=15.1$ bar, respectively. The experiments of Mettal et al. ${ }^{18}$ are conducted for $\mathrm{MCH} / \mathrm{O}_{2} / \mathrm{N}_{2}$ mixtures with Ar dilution, albeit with higher pressure, the measured ignition delays are longer than that of Pitz et al. ${ }^{4}$ It is worth noting that ignition delays $\tau$ measured by Pitz et al. ${ }^{4}$ are scaled to $p=12$ atm using the power law $\tau \propto p^{-0.98}$ recommended by Vanderover et al. ${ }^{5}$ to provide useful comparison. At $p=12$ atm, both mechanisms well reproduce the experimental measurements in the temperature range. At $p=15.1$ bar, the ignition delays are underpredicted by both mechanisms in the NTC region. Considering the estimated uncertainty of the experimental data of the ignition delays is typically $\pm 20 \%$, the predictions are still 

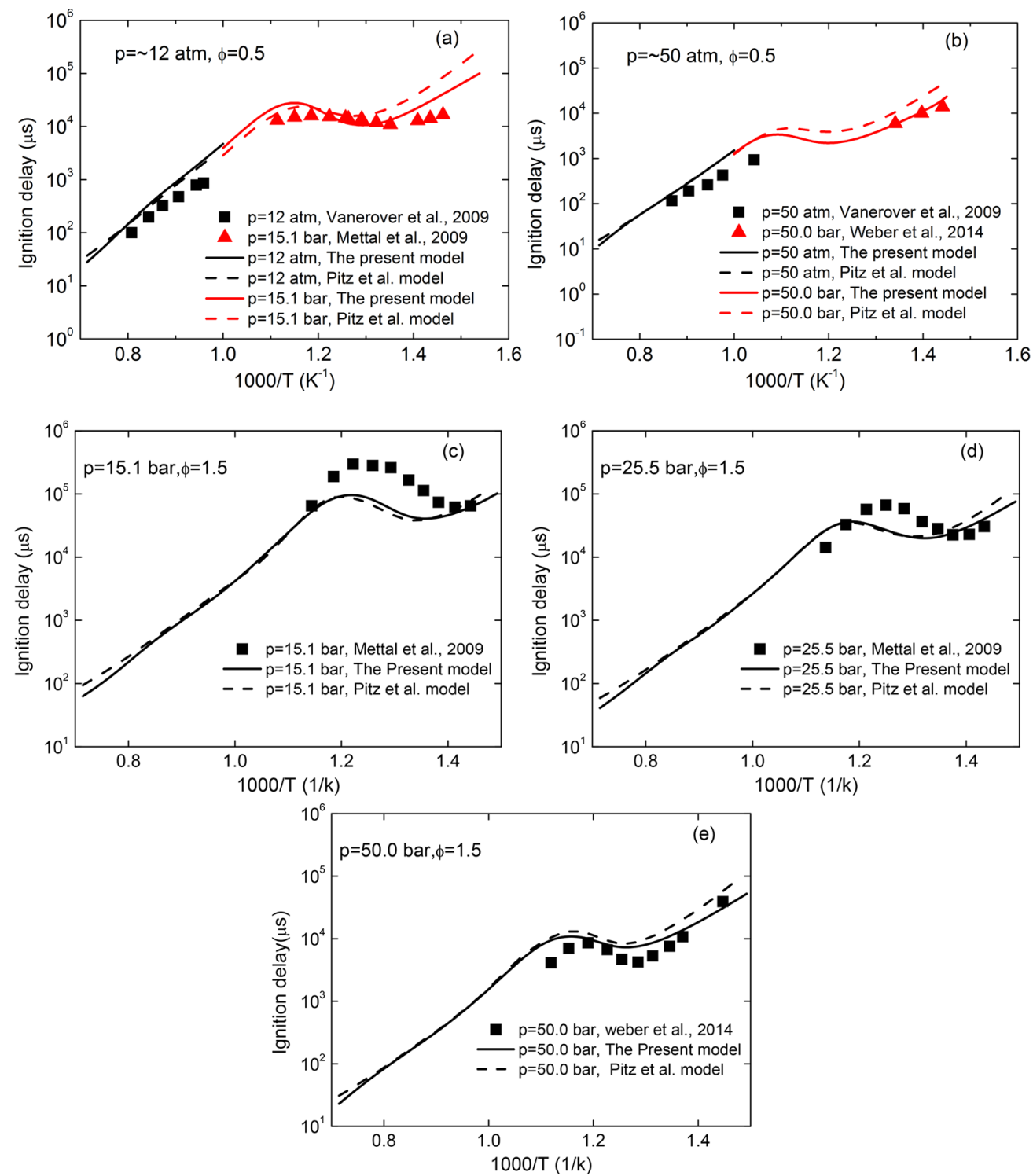

Figure 2. Comparison of experimental ${ }^{5,8,9}$ and calculated ignition delays of $\mathrm{MCH}$ at various pressures and equivalence ratios: (a) $p=\sim 12$ atm, $\varphi=$ 0.5 (b) $p=\sim 50$ atm, $\varphi=0.5$ (c) $p=15.1$ bar, $\varphi=1.5$ (d) $p=25.5$ bar, $\varphi=1.5$ (e) $p=50.0$ bar, $\varphi=1.5$.

reasonable. Nevertheless, the present mechanism shows the same accuracy with the detailed Pitz et al. ${ }^{4}$ mechanism in the high-temperature and NTC region, and even superiority at $T<$ $700 \mathrm{~K}$, which indicates the prediction capability of the optimized low-temperature submechanism in the present mechanism.

Figure $1 \mathrm{~b}$ shows a comparison between experimental data and simulations at stoichiometric ratio and $p=\sim 20 \mathrm{~atm}$. It can be seen that, in the high-temperature region $T>1000 \mathrm{~K}$, predictions by the present mechanism are consistent with the detailed Pitz et al. ${ }^{4}$ mechanism, although both mechanisms predicting slower ignition delays compared with experimental data by Vasu et al. ${ }^{6}$ at $p=20 \mathrm{~atm}$. In the NTC region $700 \mathrm{~K}<$ $T<1000 \mathrm{~K}$, the present mechanism predicts shorter ignition delays than the Pitz et al. ${ }^{4}$ mechanism by a factor of 2 at $p=20$ atm. However, experimental data is absent in this region. Improvements have been achieved by the present mechanism in the low-temperature region $T<700 \mathrm{~K}$, where the Pitz et al. ${ }^{4}$ mechanism overpredicts the ignition delays.
Figure 1c shows calculated and measured ignition delays at $p$ $=\sim 50 \mathrm{~atm}$. It can be seen that the present mechanism provides better predictions compared with the Pitz et al. mechanism ${ }^{4}$ at $T<900 \mathrm{~K}$.

Autoignition of combustible mixtures in real engines does not always happen in the stoichiometric ratio region. Lean and rich cases with equivalence ratios $\varphi=0.5$ and $\varphi=1.5$ are simulated with the present mechanism and Pitz et al. ${ }^{4}$ mechanism at various pressures. The results are shown in Figure 2.

In Figure 2a,b, at $p=\sim 12$ and 50 atm, and $\varphi=0.5$, overall predictions of ignition delays by the present mechanism agree well with the experimental data, especially for the lowtemperature region. Albeit, experimental data of ignition delays under high temperatures is absent at $\varphi=1.5$ in Figure $2 \mathrm{c}-\mathrm{e}$, satisfactory predictions by the present mechanism are obtained when comparing with the detailed Pitz et al. ${ }^{4}$ mechanism. While comparison against the experimental data at $p=15.1$ and 25.5 bar shows some differences in Figure $2 c, d$, simulations agree well with the experimental data at $p=50$ bar in Figure 2e. 

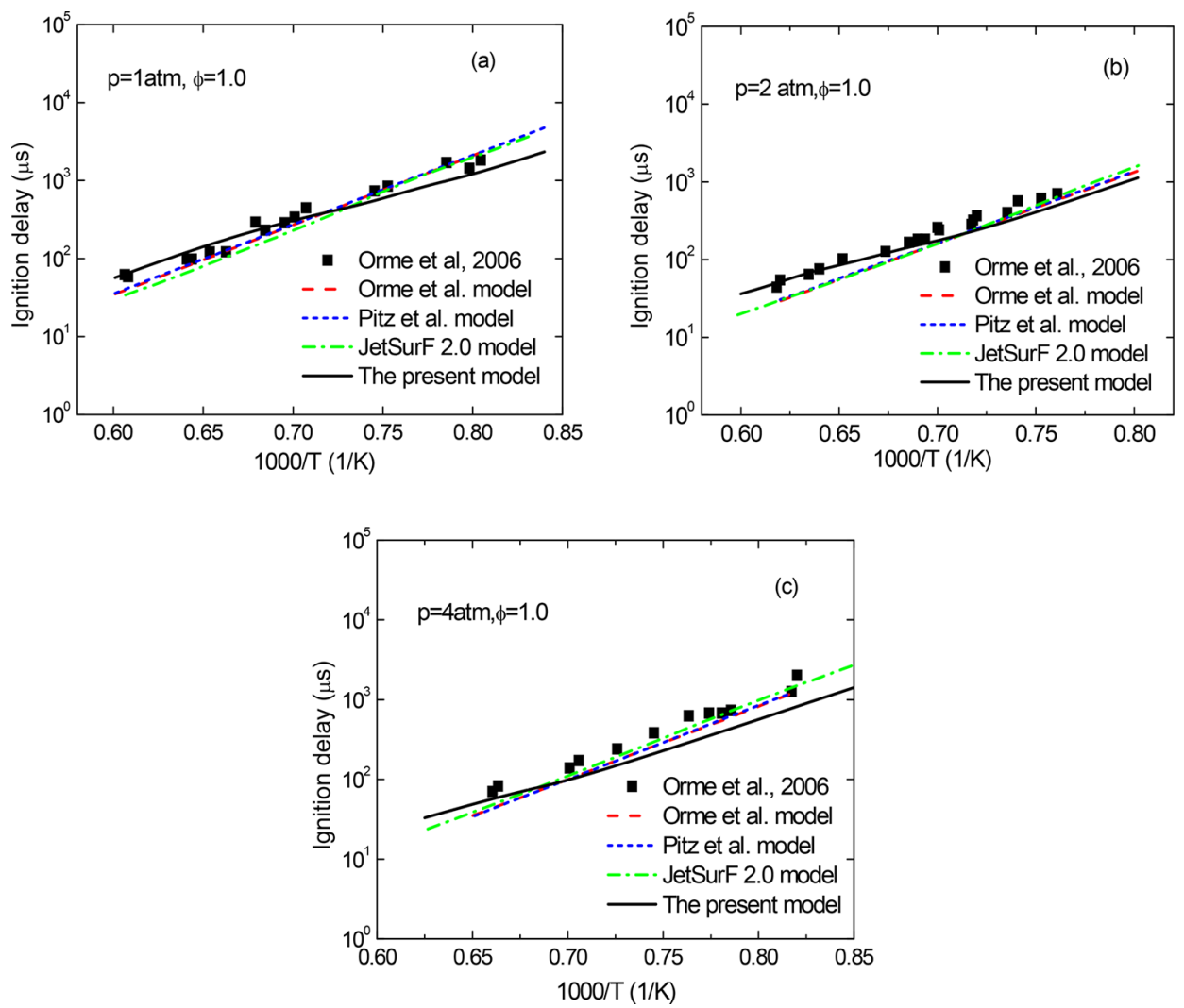

Figure 3. Comparison of experimental ${ }^{14}$ and calculated ignition delays using the present mechanism and other mechanisms ${ }^{4,14,16}$ at stoichiometric ratio and various pressures: (a) $p=1 \mathrm{~atm},(\mathrm{~b}) p=2 \mathrm{~atm},(\mathrm{c}) p=4 \mathrm{~atm}$.
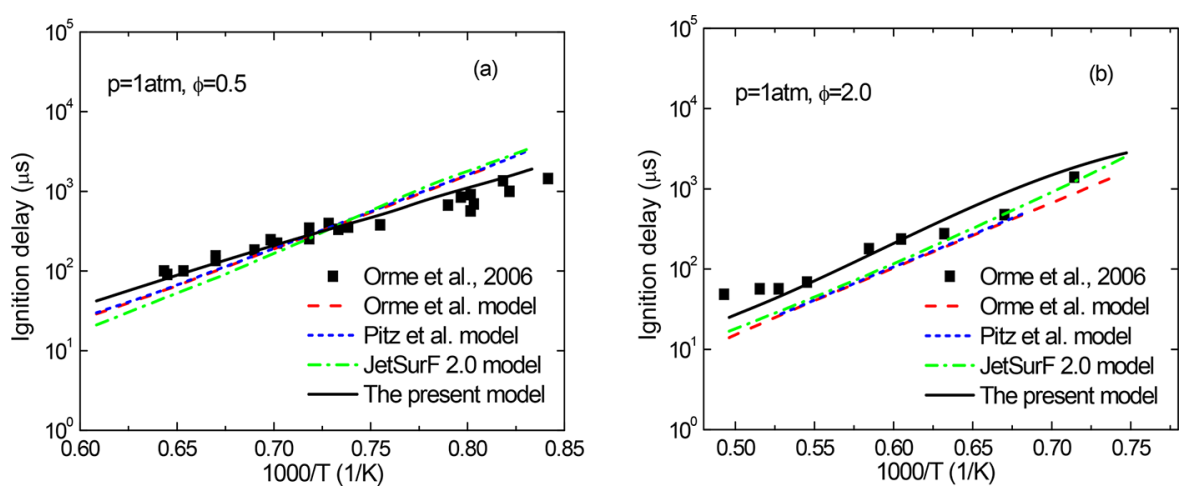

Figure 4. Comparison of experimental ${ }^{14}$ and calculated ignition delays using the present mechanism and other mechanisms ${ }^{4,14,16}$ at atmospheric pressure and different stoichiometric ratios: (a) $\varphi=0.5$, (b) $\varphi=2.0$.

However, considering the uncertainty in these experimental data, the predictions by the present mechanism remain favorable.

3.2. Autoignition Delays at Low Pressures. Orme et al. ${ }^{14}$ measured ignition delays at low pressures $(p=1-4 \mathrm{~atm})$, temperatures $(T=1200-2100 \mathrm{~K})$, and equivalence ratios $(\varphi=$ 0.5-2.0). Further calculations of the ignition delays are performed to validate the present mechanism at low pressures in Figures 3 and 4. Detailed MCH mechanisms from literatures including the Orme et al. mechanism, ${ }^{14}$ Pitz et al. mechanism, ${ }^{4}$ and JetSurF 2.0 mechanism $^{16}$ are used for comparison. The simulations are performed under the same conditions as experiment. Predictions by the present mechanism show some differences from the other three mechanisms, which almost coincide. The differences may be caused by the simplification of the present mechanism. Overall, a good agreement is obtained for ignition delays between the present mechanism and the experimental data, considering the scatter in these experimental data.

3.3. OH Time Histories during Autoignition. Vasu et al. ${ }^{7}$ measured $\mathrm{OH}$ concentration time histories during $\mathrm{MCH}$ oxidation behind reflected shock waves in a heated, highpressure shock tube. Experimental conditions covered temperatures $T=1121-1332 \mathrm{~K}$, pressures $p=15 \mathrm{~atm}$, and initial fuel concentrations of 750 and $1000 \mathrm{ppm}$ (by volume), and an equivalence ratio of 0.5 with $\mathrm{O}_{2}$ as the oxidizer and argon as the bath gas. Figure 5 shows the comparison between the experimental data and calculations with different mechanisms (JetSurF 2.0 mechanism, ${ }^{16}$ Pitz et al. mechanism, ${ }^{4}$ and the 

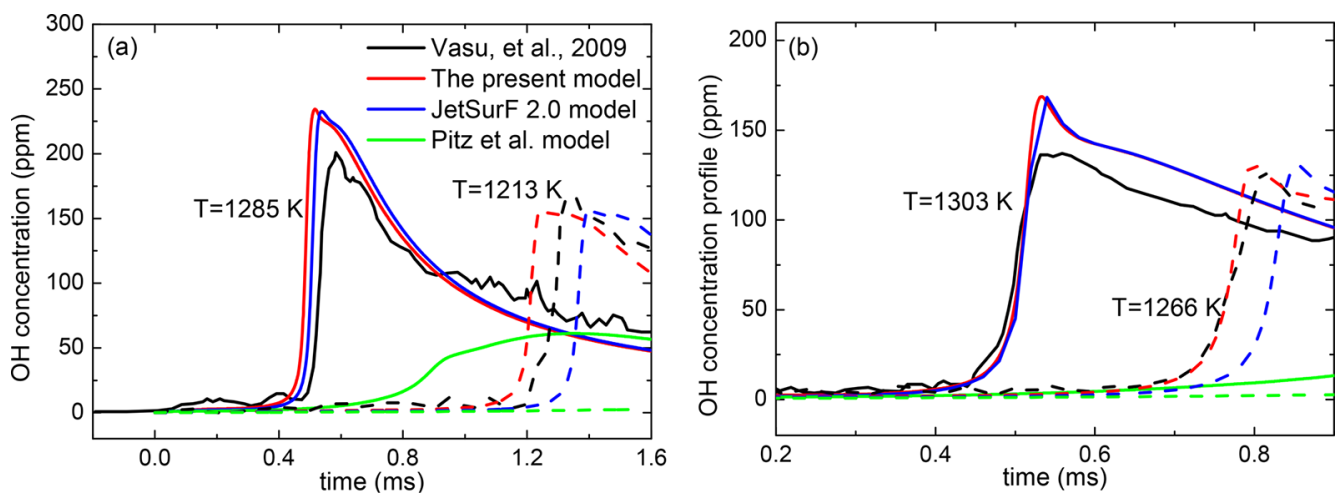

Figure 5. Comparison of experimental ${ }^{7}$ and calculated $\mathrm{OH}$ time histories with different mechanisms ${ }^{4,16}$ (using different colors) at $p=16$ atm, $\varphi=$ 0.5 , and various initial $\mathrm{MCH}$ concentrations. (a) $X_{\mathrm{MCH}}=1000 \mathrm{ppm}$, solid lines - initial temperature $T=1285 \mathrm{~K}$, dashed lines - initial temperature $T$ $=1213 \mathrm{~K}$. (b) $X_{\mathrm{MCH}}=750 \mathrm{ppm}$, solid lines - initial temperature $T=1303 \mathrm{~K}$, dashed lines - initial temperature $T=1266 \mathrm{~K}$.
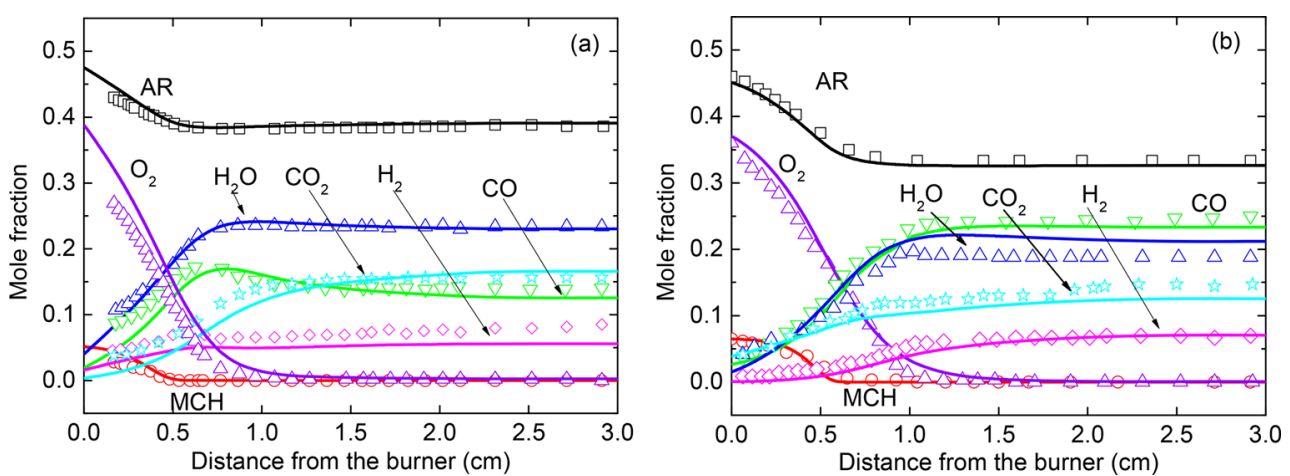

Figure 6. Measured ${ }^{12}$ (symbols) and simulated (solid lines) mole fraction profiles of major species in premixed flames with various equivalence ratios: (a) $\varphi=1.25$, (b) $\varphi=1.75$.

present mechanism) under various temperatures and initial $\mathrm{MCH}$ concentrations.

In Figure $5 \mathrm{a}$, at $T=1285 \mathrm{~K}$, both the present mechanism and JetSurF 2.0 mechanism ${ }^{16}$ well predict the shape of $\mathrm{OH}$ profiles with less than $10 \%$ overprediction of the peak value. However, the Pitz et al. ${ }^{4}$ mechanism predicts a much slower rise during ignition and a near flat peak in contrast to the sharp peak observed during experiments. As the temperature decreases to $T=1213 \mathrm{~K}$, the present mechanism predicts an earlier increasing of $\mathrm{OH}$ while JetSurF 2.0 predicts a delayed increasing. Both the two mechanisms are within the uncertainty of the experimental data. However, $\mathrm{OH}$ concentration predicted by the Pitz et al. ${ }^{4}$ mechanism rises even slower than $T=1285 \mathrm{~K}$ and barely changes during the residence time. Vasu et al. ${ }^{7}$ indicate that the discrepancies predicted by the Pitz et al. $^{4}$ mechanism may be caused by inaccuracy of higher hydrocarbons radical chemistry (such as those linking cyclic- $\mathrm{C}_{7}$ to $n-\mathrm{C}_{7}$ species).

For an initial MCH concentration of $750 \mathrm{ppm}$ and $T=1303$ $\mathrm{K}$ in Figure $5 \mathrm{~b}$, predictions by the present mechanism are consistent with the JetSurF 2.0 mechanism ${ }^{16}$ and agree with the experimental data well within $25 \%$ overprediction of the $\mathrm{OH}$ profile after ignition. At temperature $T=1266 \mathrm{~K}$, improvement is achieved in predicting the onset of $\mathrm{OH}$ increasing by the present mechanism compared wih the JetSurF 2.0 mechanism. $^{16}$

3.4. Species Profiles in Laminar Premixed Flames. Wang et al. ${ }^{12}$ investigated the species formed in the premixed flame of $\mathrm{MCH}$ at equivalence ratios $\varphi=1.25$ and $\varphi=1.75$, and $p=30$ Torr. The concentrations of a number of reactants, products, stable intermediates, and radicals have been quantified. Predictions by the present mechanism are compared to the experimental data from Wang et al. ${ }^{12}$ in this section. The experimental temperature profiles are used as input data in simulations.

The comparison of mole fractions between calculated and experimental results for $\mathrm{MCH}, \mathrm{O}_{2}, \mathrm{H}_{2}, \mathrm{CO}, \mathrm{CO}_{2}, \mathrm{H}_{2} \mathrm{O}$, and $\mathrm{Ar}$ is shown in Figure 6. In Figure 6, the present mechanism is shown to be capable of reproducing the main experimental observations on reactants and products within $15 \%$ error on average. $\mathrm{MCH}$ is mainly consumed by thermal decomposition and radicals attack, leading to $\mathrm{H}$-abstraction, while the residual oxygen is consumed by the combustion of intermediates after the complete consumption of the fuel. With the consumption of $\mathrm{MCH}$ and $\mathrm{O}_{2}, \mathrm{CO}$ and $\mathrm{H}_{2} \mathrm{O}$ increase steadily on the flame front. In the lean and stoichiometric cases, the main source of $\mathrm{CO}$ is from three reactions of $\mathrm{HCO}$ with $\mathrm{OH}, \mathrm{H}_{2} \mathrm{O}$, and $\mathrm{M}$. However, under fuel rich conditions, the path $\mathrm{C}_{2} \mathrm{H}_{2} \rightarrow \mathrm{HCCO}$ $\rightarrow \mathrm{CO}$ becomes more important and can be dominant. $\mathrm{CO}$ is further consumed to form $\mathrm{CO}_{2}$ mainly through the slow reaction $\mathrm{CO}+\mathrm{OH}=\mathrm{CO}_{2}+\mathrm{H}$. When the mixture becomes richer as is shown in Figure $6 \mathrm{~b}$, the decay of $\mathrm{CO}$ is not obvious and the concentration of $\mathrm{CO}$ is high at the postflame zone because there are not enough $\mathrm{OH}$ radicals in the very rich flame condition. In general, the simulated results match the mole expansion effect. The overall agreement between the calculations and experimental measurements on the consumption of $\mathrm{MCH}$ and $\mathrm{O}_{2}$, and the formation of $\mathrm{H}_{2}, \mathrm{H}_{2} \mathrm{O}$, $\mathrm{CO}$, and $\mathrm{CO}_{2}$, offers a preliminary validation of the present mechanism for flames. 
The oxidation kinetics of small species $\left(<\mathrm{C}_{4}\right)$ is extremely important for flame speeds, heat release, and emissions. As a result, it is important to validate small species profiles in flames. Simulated and measured mole fraction profiles of several main small species are shown in Figures 7 and 8. It should be noted

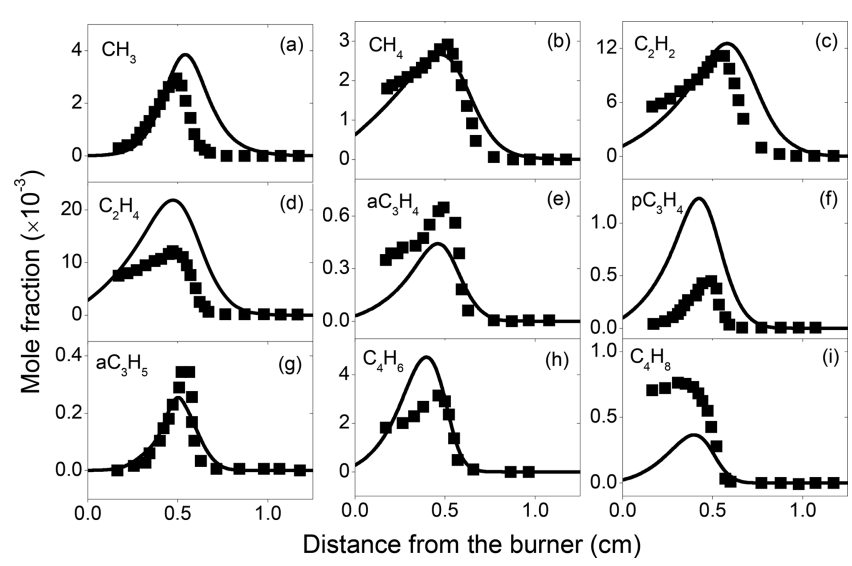

Figure 7. Measured $^{12}$ (symbols) and simulated (lines) mole fraction profiles of the intermediates in the premixed flame with equivalence ratio $\varphi=1.25$.

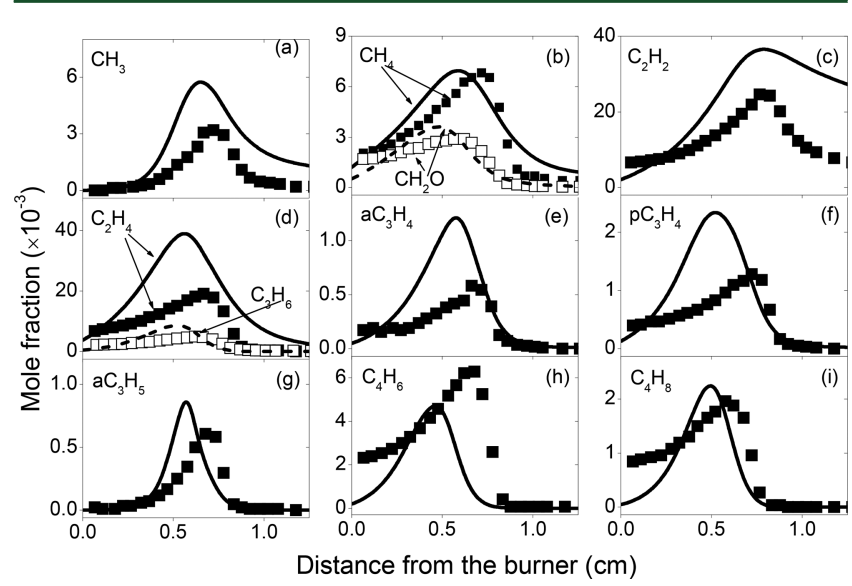

Figure 8. Measured $^{12}$ (symbols) and simulated (lines) mole fraction profiles of the intermediates in the premixed flame with equivalence ratio $\varphi=1.75$.

that there exists a discrepancy between experiment and simulation close to the burner surface, which is mainly caused by the perturbation of the sampling nozzle. Thus, the measured data at distances shorter than $2 \mathrm{~mm}$ from the burner surface might not represent the true mole fractions of the measured species. Considering uncertainty of experimental data in measuring small species, satisfactory agreements within a factor of 2 have been achieved with the present mechanism.

In Figures 7 and 8 , as the equivalence ratio increases from $\varphi$ $=1.25$ to $\varphi=1.75$, small species concentrations increase. Concentrations of $\mathrm{C}_{2}$ species $\left(\mathrm{C}_{2} \mathrm{H}_{4}\right.$ and $\left.\mathrm{C}_{2} \mathrm{H}_{2}\right)$ are relatively higher than other species in both flames. It is worth noting that the concentration of 1,3-butadiene $\mathrm{C}_{4} \mathrm{H}_{6}$ is higher than $\mathrm{C}_{3}$ species. A good description of the $\mathrm{C}_{4} \mathrm{H}_{6}$ submechanism is important for $\mathrm{MCH}$ oxidation, as reaction path analysis of the present mechanism shows that nearly all $\mathrm{MCH}$ decomposes through $\mathrm{C}_{4} \mathrm{H}_{6}$, which was also indicated in previous studies. ${ }^{7}$ The main consuming path of $\mathrm{C}_{4} \mathrm{H}_{6}$ is to react with $\mathrm{H}$ atom and then decomposes to $\mathrm{C}_{2} \mathrm{H}_{4}, \mathrm{nC}_{4} \mathrm{H}_{5}$, and $\mathrm{iC}_{4} \mathrm{H}_{5} . \mathrm{nC}_{4} \mathrm{H}_{5}$ and
$\mathrm{iC}_{4} \mathrm{H}_{5}$ undergo oxidation and decomposition to form smaller species, e.g., $\mathrm{C}_{2} \mathrm{H}_{3}, \mathrm{CH}_{2} \mathrm{CO}$, and $\mathrm{CH}_{2} \mathrm{CHO}$.

Propene $\left(\mathrm{C}_{3} \mathrm{H}_{6}\right)$ is a product of $\mathrm{C}_{7}$ species decomposition. $\mathrm{C}_{3} \mathrm{H}_{6}$ then converts to $\mathrm{C}_{3} \mathrm{H}_{5}$ through $\mathrm{H}$-abstraction by $\mathrm{H}, \mathrm{O}$, $\mathrm{OH}$, and most of $\mathrm{aC}_{3} \mathrm{H}_{4}$ come from $\mathrm{H}$-abstraction of $\mathrm{aC}_{3} \mathrm{H}_{5}$. $\mathrm{aC}_{3} \mathrm{H}_{4}$ consumes through isomerization to form $\mathrm{pC}_{3} \mathrm{H}_{4}$, which then decomposes and yields $\mathrm{C}_{2} \mathrm{H}_{2}$. The present mechanism does not consider the reaction paths of $\mathrm{aC}_{3} \mathrm{H}_{4}$ and $\mathrm{pC}_{3} \mathrm{H}_{4}$ forming $\mathrm{C}_{3} \mathrm{H}_{3}$. This simplification may explain the overprediction of $\mathrm{aC}_{3} \mathrm{H}_{4}$ and $\mathrm{pC}_{3} \mathrm{H}_{4}$ by a factor of 2 , while the overall agreement is still reasonable.

Similarly, ethylene $\left(\mathrm{C}_{2} \mathrm{H}_{4}\right)$ is consumed by $\mathrm{H}$-abstraction to produce vinyl $\left(\mathrm{C}_{2} \mathrm{H}_{3}\right)$ radicals and subsequently form $\mathrm{C}_{2} \mathrm{H}_{2}$ through $\mathrm{C}_{2} \mathrm{H}_{3}+\mathrm{M}=\mathrm{C}_{2} \mathrm{H}_{2}+\mathrm{H}+\mathrm{M}$; the $\mathrm{C}_{2} \mathrm{H}_{3}$ radicals are the main source of $\mathrm{C}_{2} \mathrm{H}_{2} \cdot \mathrm{C}_{2} \mathrm{H}_{2}$ reacts with $\mathrm{O}$ atom to produce $\mathrm{HCCO}$, which then leads to $\mathrm{CO}$.

Methane $\left(\mathrm{CH}_{4}\right)$ is mainly formed from $\mathrm{H}$ addition to methyl radical. The main consumption paths of $\mathrm{CH}_{4}$ are the reactions with $\mathrm{H}, \mathrm{O}$, and $\mathrm{OH}$ radicals. Predictions of $\mathrm{CH}_{4}$ and $\mathrm{CH}_{3}$ by the present mechanism are in good agreement with the experimental measurement.

3.5. Laminar Flame Speeds. Several experiments studied laminar flame speeds of $\mathrm{MCH} /$ air mixtures using different flame configurations. Wu et al. ${ }^{10}$ measured flames speeds of spherically expanding flames at unburnt temperature $T_{0}=353$ $\mathrm{K}$ and $p=1-10 \mathrm{~atm}$. Ji et al. ${ }^{11}$ measured flames speeds in a counterflow configuration at $T_{0}=353 \mathrm{~K}$ and $p=1 \mathrm{~atm}$. Figure 9 presents the comparison of predicted laminar flame speeds

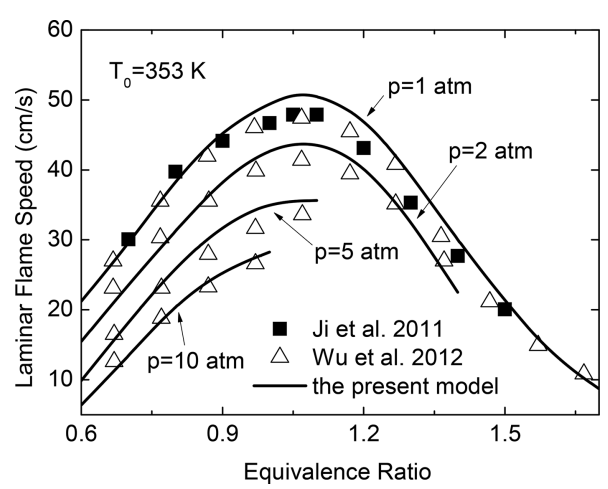

Figure 9. Measured (symbols) $)^{10,11}$ and calculated (lines) laminar flame speeds of $\mathrm{MCH} /$ air mixtures as a function of equivalence ratio at various pressures and equivalence ratios, and unburnt gas temperature $T_{0}=353 \mathrm{~K}$.

using the present mechanism against experimental data. ${ }^{10,11}$ Considering the experimental uncertainty, the flame speeds predicted by the present mechanism show satisfactory agreement with the experimental data under various pressures within a variation of $4 \mathrm{~cm}$.

\section{CONCLUSIONS}

We developed a new compact mechanism consisting of 70 species and 377 reactions for $\mathrm{MCH}$ autoignition and combustion under engine relevant conditions. The aim was to retain only a small number of species and reactions without losing accuracy. This was accomplished by combining the hightemperature $\mathrm{C}_{5}-\mathrm{C}_{7}$ submechanism with a simplified $\mathrm{C}_{0}-\mathrm{C}_{4}$ kernel, and an optimized semiglobal low-temperature submechanism. In the low-temperature submechanism, species 
isomers and reaction pathways were lumped into one chain, which could reproduce the NTC behaviors in ignition delays.

Extensive validations of the present mechanism were performed through comparing with experimental data available in literatures, with special emphasis on the engine relevant operating conditions in a wide range of temperatures (650$2000 \mathrm{~K})$, pressures (1-50 atm), and equivalence ratios (0.52.0). The experimental data for validation included ignition delays in shock tubes and rapid compression machines, as well as $\mathrm{OH}$ time histories in a heated, high-pressure shock tube. Moreover, laminar premixed flame experimental data, including species concentration profiles and flame speeds, provided further validations. The results indicated that predictions by this mechanism agree with the experimental data.

On average, our mechanism contains $93 \%$ fewer species and $91 \%$ fewer reactions, respectively, in comparison to the detailed Pitz et al. mechanism. ${ }^{4}$ The computational time can be reduced by an order of magnitude for the reduction in species numbers. For example, in the homogeneous calculations, the CPU time is less than $1 \mathrm{~s}$ when using the present mechanism, whereas the CPU time is $13 \mathrm{~s}$ with the detailed mechanism. The homogeneous reactor is the simplest model that only involves time evolution of the species and temperature. The computational time is within the order of seconds even for the detailed mechanism. However, for one-dimensional premixed flame computations, the computational time can be enormous when spatial convection and diffusion are involved, which is beyond the capability of the current laptops. Despite the great simplification, the present mechanism does not introduce significant errors and performs similarly to the detailed mechanisms in predicting ignition and combustion characteristics. With its compact size, the present mechanism is promising for multidimensional engine simulations, which merits further investigations.

\section{ASSOCIATED CONTENT}

\section{S Supporting Information}

The Supporting Information is available free of charge on the ACS Publications website at DOI: 10.1021/acs.energyfuels.7b01224.

The newly developed mechanism for autoignition and combustion of $\mathrm{MCH}$ (TXT)

Thermal data (TXT)

Lennard-Jones parameters (TXT)

\section{AUTHOR INFORMATION}

\section{Corresponding Authors}

*E-mail: zhongbj@tsinghua.edu.cn (B.-J.Z.).

*E-mail: k.luo@ucl.ac.uk (K.H.L.).

\section{ORCID}

Tong Yao: 0000-0001-8499-015X

\section{Notes}

The authors declare no competing financial interest.

\section{ACKNOWLEDGMENTS}

This work is supported by the Natural Science Foundation of China (NSFC) under Contracts No. 91441113 and No. 91441120. Computing resources were from the ARCHER funded by the UK Engineering and Physical Sciences Research Council (EPSRC) under the project "UK Consortium on Mesoscale Engineering Sciences (UKCOMES)” (Grant No.
EP/L00030X/1) and the project "High Performance Computing Support for United Kingdom Consortium on Turbulent Reacting Flow (UKCTRF)" (Grant No. EP/K024876/1).

\section{REFERENCES}

(1) Edwards, T.; Maurice, L. Q. Surrogate mixtures to represent complex aviation and rocket fuels. J. Propul. Power 2001, 17 (2), 461466.

(2) Humer, S.; Frassoldati, A.; Granata, S.; Faravelli, T.; Ranzi, E.; Seiser, R.; Seshadri, K. Experimental and kinetic modeling study of combustion of JP-8, its surrogates and reference components in laminar nonpremixed flows. Proc. Combust. Inst. 2007, 31 (1), 393400.

(3) Violi, A.; Yan, S.; Eddings, E. G.; Sarofim, A. F.; Granata, S.; Faravelli, T.; Ranzi, E. Experimental formulation and kinetic model for JP-8 surrogate mixtures. Combust. Sci. Technol. 2002, 174 (11-12), 399-417.

(4) Pitz, W. J.; Naik, C.; Mhaoldúin, T. N.; Westbrook, C. K.; Curran, H. J.; Orme, J. P.; Simmie, J. Modeling and experimental investigation of methylcyclohexane ignition in a rapid compression machine. Proc. Combust. Inst. 2007, 31 (1), 267-275.

(5) Vanderover, J.; Oehlschlaeger, M. A. Ignition time measurements for methylcylcohexane- and ethylcyclohexane-air mixtures at elevated pressures. Int. J. Chem. Kinet. 2009, 41 (2), 82-91.

(6) Vasu, S. S.; Davidson, D. F.; Hong, Z.; Hanson, R. K. Shock tube study of methylcyclohexane ignition over a wide range of pressure and temperature. Energy Fuels 2009, 23 (1), 175-185.

(7) Vasu, S. S.; Davidson, D. F.; Hanson, R. K. OH time-histories during oxidation of $n$-heptane and methylcyclohexane at high pressures and temperatures. Combust. Flame 2009, 156 (4), 736-749.

(8) Mittal, G.; Sung, C.-J. Autoignition of methylcyclohexane at elevated pressures. Combust. Flame 2009, 156 (9), 1852-1855.

(9) Weber, B. W.; Pitz, W. J.; Mehl, M.; Silke, E. J.; Davis, A. C.; Sung, C.-J. Experiments and modeling of the autoignition of methylcyclohexane at high pressure. Combust. Flame 2014, 161 (8), 1972-1983.

(10) Wu, F.; Kelley, A. P.; Law, C. K. Laminar flame speeds of cyclohexane and mono-alkylated cyclohexanes at elevated pressures. Combust. Flame 2012, 159 (4), 1417-1425.

(11) Ji, C.; Dames, E.; Sirjean, B.; Wang, H.; Egolfopoulos, F. N. An experimental and modeling study of the propagation of cyclohexane and mono-alkylated cyclohexane flames. Proc. Combust. Inst. 2011, 33 (1), 971-978.

(12) Wang, Z.; Ye, L.; Yuan, W.; Zhang, L.; Wang, Y.; Cheng, Z.; Zhang, F.; Qi, F. Experimental and kinetic modeling study on methylcyclohexane pyrolysis and combustion. Combust. Flame 2014, 161 (1), 84-100.

(13) Skeen, S. A.; Yang, B.; Jasper, A. W.; Pitz, W. J.; Hansen, N. Chemical structures of low-pressure premixed methylcyclohexane flames as benchmarks for the development of a predictive combustion chemistry model. Energy Fuels 2011, 25 (12), 5611-5625.

(14) Orme, J.; Curran, H.; Simmie, J. Experimental and modeling study of methyl cyclohexane pyrolysis and oxidation. J. Phys. Chem. A 2006, 110 (1), 114-131.

(15) Narayanaswamy, K.; Pitsch, H.; Pepiot, P. A chemical mechanism for low to high temperature oxidation of methylcyclohexane as a component of transportation fuel surrogates. Combust. Flame 2015, 162 (4), 1193-1213.

(16) Wang, H.; Dames, E.; Sirjean, B.; Sheen, D. A.; Tangko, R.; Violi, A.; Lai, J. Y. W.; Egolfopoulos, F. N.; Davidson, D. F.; Hanson, R. K.; Bowman, C. T.; Law, C. K.; Tsang, W.; Cernansky, N. P.; Miller, D. L.; Lindstedt, R. P. JetSurF version 2.0: A high-temperature chemical kinetic model of $n$-alkane (up to n-dodecane), cyclohexane, and methyl-, ethyl-, n-propyl and n-butyl-cyclohexane oxidation at high temperatures; Sept 19, 2010. http://melchior.usc.edu/JetSurF/JetSurF2.0.

(17) Bikas, G.; Peters, N. Kinetic modelling of $n$-decane combustion and autoignition: Modeling combustion of $n$-decanem. Combust. Flame 2001, 126 (1-2), 1456-1475. 
(18) Chang, Y.; Jia, M.; Liu, Y.; Li, Y.; Xie, M. Development of a new skeletal mechanism for $n$-decane oxidation under engine-relevant conditions based on a decoupling methodology. Combust. Flame 2013, $160(8), 1315-1332$.

(19) Chang, Y.; Jia, M.; Liu, Y.; Li, Y.; Xie, M.; Yin, H. Application of a decoupling methodology for development of skeletal oxidation mechanisms for heavy $n$-alkanes from $n$-octane to $n$-hexadecane. Energy Fuels 2013, 27 (6), 3467-3479.

(20) You, X.; Egolfopoulos, F. N.; Wang, H. Detailed and simplified kinetic models of $n$-dodecane oxidation: The role of fuel cracking in aliphatic hydrocarbon combustion. Proc. Combust. Inst. 2009, 32 (1), 403-410.

(21) Yao, T.; Zhong, B.-J. Chemical kinetic model for auto-ignition and combustion of $n$-decane. Acta Phys. Chim. Sin. 2013, 29 (2), $237-$ 244.

(22) Yao, T.; Pei, Y.; Zhong, B. J.; Som, S.; Lu, T.; Luo, K. H. A compact skeletal mechanism for $n$-dodecane with optimized semiglobal low-temperature chemistry for diesel engine simulations. Fuel 2017, 191, 339-349.

(23) Tian, Z.; Zhang, Y.; Yang, F.; Huang, Z. Comparative study on autoignition characteristics of methylcyclohexane and cyclohexane. Energy Fuels 2015, 29 (4), 2685-2695.

(24) Tsang, W. Chemical kinetic data base for combustion chemistry part 4: Isobutane. J. Phys. Chem. Ref. Data 1990, 19 (1), 1-68.

(25) Wang, H.; You, X.; Joshi, A. V.; Davis, S. G.; Laskin, A.; Egolfopoulos, F.; Law, C. K. USC Mech Version II: High-Temperature Combustion Reaction Model of $\mathrm{H}_{2} / \mathrm{CO} / \mathrm{C}_{1}-\mathrm{C}_{4}$ Compounds; University of Southern California: Los Angeles, CA, 2007. http://ignis.usc.edu/ USC Mech II.htm.

(26) Chakir, A.; Bellimam, M.; Boettner, J. C.; Cathonnet, M. Kinetic study of $n$-heptane oxidation. Int. J. Chem. Kinet. 1992, 24 (4), 385410.

(27) Curran, H. J.; Gaffuri, P.; Pitz, W. J.; Westbrook, C. K. A comprehensive modeling study of iso-octane oxidation. Combust. Flame 2002, 129 (3), 253-280.

(28) Olivella, S.; Sole, A.; Bofill, J. M. A theoretical investigation of the thermal ring opening of cyclopropyl radical into allyl radical. Evidence for a highly nonsymmetric transition state. J. Am. Chem. Soc. 1990, 112 (6), 2160-2167.

(29) Smith, D. M.; Nicolaides, A.; Golding, B. T.; Radom, L. Ring opening of the cyclopropylcarbinyl radical and its $\mathrm{n}$ - and o-substituted analogues: A theoretical examination of very fast unimolecular reactions. J. Am. Chem. Soc. 1998, 120 (39), 10223-10233.

(30) Martinez, F. N.; Schlegel, H. B.; Newcomb, M. Ab initio molecular orbital calculations of ring opening of cyclopropylcarbinyl radicals. J. Org. Chem. 1996, 61 (24), 8547-8550.

(31) Martinez, F. N.; Schlegel, H. B.; Newcomb, M. Ab initio molecular orbital calculations of electronic effects on the kinetics of cyclopropylcarbinyl radical ring openings. J. Org. Chem. 1998, 63 (11), 3618-3623.

(32) Matheu, D. M.; Green, W. H.; Grenda, J. M. Capturing pressure-dependence in automated mechanism generation: Reactions through cycloalkyl intermediates. Int. J. Chem. Kinet. 2003, 35 (3), 95119.

(33) Sirjean, B.; Glaude, P.-A.; Ruiz-Lopez, M.; Fournet, R. Theoretical kinetic study of thermal unimolecular decomposition of cyclic alkyl radicals. J. Phys. Chem. A 2008, 112 (46), 11598-11610.

(34) Zeppieri, S. P.; Klotz, S. D.; Dryer, F. L. Modeling concepts for larger carbon number alkanes: A partially reduced skeletal mechanism for $n$-decane oxidation and pyrolysis. Proc. Combust. Inst. 2000, 28 (2), $1587-1595$.

(35) Silke, E. J.; Pitz, W. J.; Westbrook, C. K.; Ribaucour, M. Detailed chemical kinetic modeling of cyclohexane oxidation. J. Phys. Chem. A 2007, 111 (19), 3761-3775.

(36) McGivern, W. S.; Awan, I. A.; Tsang, W.; Manion, J. A. Isomerization and decomposition reactions in the pyrolysis of branched hydrocarbons: 4-methyl-1-pentyl radical. J. Phys. Chem. A 2008, 112 (30), 6908-6917.
(37) Curran, H. J. Rate constant estimation for $\mathrm{C}_{1}$ to $\mathrm{C}_{4}$ alkyl and alkoxyl radical decomposition. Int. J. Chem. Kinet. 2006, 38 (4), 250275.

(38) Tsang, W.; McGivern, W. S.; Manion, J. A. Multichannel decomposition and isomerization of octyl radicals. Proc. Combust. Inst. 2009, 32 (1), 131-138.

(39) Warnatz, J.; Maas, U.; Dibble, R. W. Combustion: Physical and Chemical Fundamentals, Modeling and Simulation, Experiments, Pollutant Formation; Springer: Berlin, 2001; pp 101-103.

(40) Rabitz, H.; Kramer, M.; Dacol, D. Sensitivity analysis in chemical kinetics. Annu. Rev. Phys. Chem. 1983, 34 (1), 419-61.

(41) Turányi, T. Sensitivity analysis of complex kinetic systems. Tools and applications. J. Math. Chem. 1990, 5 (3), 203-48.

(42) Wang, Q. D. Skeletal mechanism generation for hightemperature combustion of $\mathrm{H}_{2} / \mathrm{CO} / \mathrm{C}_{1}-\mathrm{C}_{4}$ hydrocarbons. Energy Fuels 2013, 27 (7), 4021-4030.

(43) Lutz, A. E.; Kee, R. J.; Miller, J. A. SENKIN: A FORTRAN program for predicting homogeneous gas phase chemical kinetics with sensitivity analysis; Sandia National Laboratories Report SAND-878248; Sandia National Laboratories: Livermore, CA, 1988.

(44) Kee, R. J.; Grcar, J. F.; Smooke, M. D.; Miller, J. A. A Fortran program for modeling steady laminar one-dimensional premixed flames; Sandia National Laboratories Report SAND-85-8240; Sandia National Laboratories: Livermore, CA, 1985. 